\title{
Fluid Flow Analysis of Stern Hull MV. Kelola Mina Makmur 150 GT Based Engine Propeller and Hull Matching Using Actuator Disk Propeller Method
}

\author{
Irfan Syarif Arief ${ }^{1}$, Tony Bambang Musriyadi ${ }^{2}$, Anwar Sahid ${ }^{3}$ \\ (Received: 30 January 2019 / Revised: 29 September 2019 / Accepted: 05 March 2021)
}

\begin{abstract}
- the results of the simulation used a propeller disk actuator method that models the propeller effect without modeling a real propeller. Direct optimization will be calculated using the CFD method of each variation of the clearance propeller configuration indicating that the amount of propulsion efficiency produced is very dependent on the clearance propeller. The most optimal propulsion efficiency occurs at a distance of $0.738 \mathrm{~m}$ from the steering shaft with a Dprop $=$ $0.88, \mathrm{KT}=0.22, \mathrm{KQ}=\mathbf{0 . 0 2 8}$, and $\mathrm{J}=\mathbf{0 . 4 0}$ besides having an advance velocity visualized with a $\mathrm{Va}=10.6 \mathrm{knots}$ which has a $50 \%$ propulsion efficiency, which the value will decrease according to the reduction in distance propeller. The less efficiency of the propulsion produced in the clearance propeller between $-\mathbf{0 . 1 6 2}-0.438 \mathrm{~m}$ from the steering shaft. This is because the slope angle between the entry of water and the longitudinal axis of the ship's hull on the stern exceeds the required conditions.
\end{abstract}

Keywords - 150 GT fishing vessel, actuator disk propeller, propeller clearance, propulsion efficiency.

\section{INTRODUCTION}

\section{B} ased on observations at Juwana District Pati, all fishing vessel units in the Northern Coast area use a uniform propulsion system, which is also chosen based on traditional practices without prior calculation. So that the propulsion system on the 150 GT fishing vessel has several problems. From the development of the existing 150 GT fishing vessel, they are only able to work at speeds of 7 to 8 knots, of course, the dependence depends on the propulsion system used. This value is a small value for the size of a 150 GT fishing vessel. Because fishing vessels must also have acceleration capabilities to compensate for the speed of the fish.

The preliminary analysis of the 150 GT fishing hull design does not have a calculation and planning process on a propulsion system is engine propeller matching. The problem that usually the design of a propulsion system is that the planned service speed is not fulfilled even though the calculation has been fulfilled. An example is the case of the 150 GT Mina Makmur fishing vessel, the result of the sea trial shows that the service speed was not reached. So that in analyzing the ship propulsion system can not only by separately reviewing aspects of the ship's design, propellers, and prime movers but overall must be considered in full to get a more optimal match point. Changes in the characteristics of the three

Irfan Syarif Arief is with Department of Marine Engineering, Institut Teknologi Sepuluh Nopember, Surabaya, 60111, Indonesia. E-mail: irfansya@its.ac.id

Tony Bambang Musriyadi is with Department of Marine Engineering, Institut Teknologi Sepuluh Nopember, Surabaya, 60111, Indonesia. E-mail: toni@ne.its.ac.id

Anwar Sahid is with Department of Marine Engineering, Institut Teknologi Sepuluh Nopember, Surabaya, 60111, Indonesia. E-mail: anwarsahid48@gmail.com aspects need to be followed by re-matching because, in reality, the ship propulsion system is not general, which can be applied to the entire ship.

The low efficiency of propulsion produced by ships can be caused by i) non-uniform water flow to the propeller, ii) insufficient propeller work area, iii) slope angle between water entry and a longitudinal axis of the hull (skeg) of the stern which exceeds the required conditions. This also results in low propulsion efficiency and high vibration generated.

Based on the above phenomena, it is necessary to have a design review of propeller clearance criteria on 150 GT fishing vessels, specifically towards increasing the efficiency of ship propulsion. The method used to do the simulation using the actuator disc propeller method (momentum propeller theory). Making a hull model will be made using the Maxsurf and Rhinoceros simulation software using Numeca Fine Marine. This study aims to provide a benchmark for shipowners in modeling a propulsion system with interactions between the hull model which has the highest propulsion efficiency value.

\section{METHOD}

The methodology used in the study is a simulation based-method, which will be used as a reference for solving problems. This paper writing methodology covers all the questions that will be solved out to solve the problem or do the analysis process to the final task problem. More details are described as follows:

\section{A. Hull Design of 150 GT Fishing Vessel}

Many of these traditional Juwana fishing vessels are found in the Coastal Fisheries Port (PPP) Bajomulyo which consists of 2 units, for ships < 30 GT with cantrang, mini long line fishing, nets, and for ships $>30$ GT with catch purse seine nets and gillnet nets. Juwana 
Ship has a length of 10 to 28 meters. The speed that can be operated on this ship is between 4 and 8 knots. Generally, the engine used is a truck engine for the size of small vessels and marine engines with a larger vessel capacity. The stability of this type of ship is quite good with a rolling period of 3 to 30 seconds. The cruising power of this ship can reach more than 2000 miles of sea and can survive with waves of 2 meters [1].

150 GT fishing vessel with gillnet net, with a capacity of around 100 tons and has an engine power of
657 HP. This ship has the characteristics of a $U$ hull design. Because the manufacturing is still traditional, it is necessary to study a 150 GT hull model that focuses on the stern to get the efficiency of the propulsion system. The propulsion system used is a B-Series propeller with 4 blades and the engine used is Nissan marine diesel with a power of $650 \mathrm{HP}$. Where there is a skeg at the stern, besides being an enforcer, it can accelerate the advance velocity to the propeller as in Figure 1.

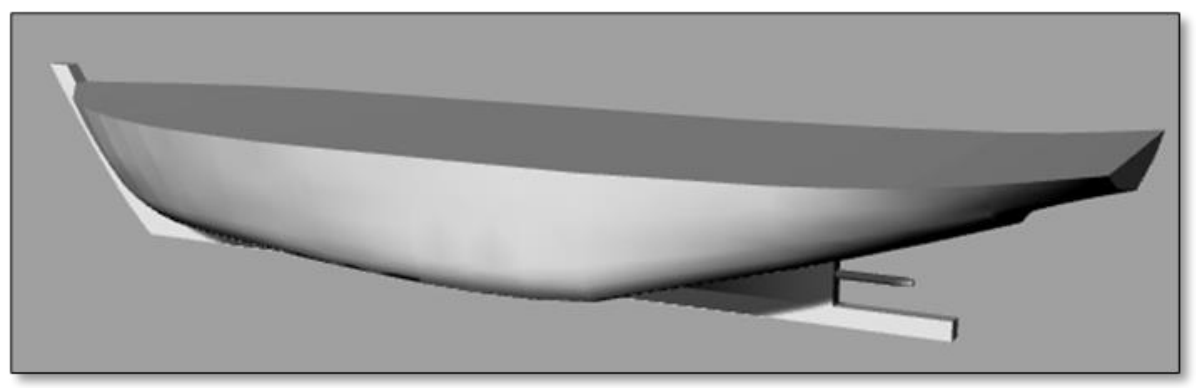

Figure. 1. The result 3D of 150 GT fishing vessel.

\section{B. Fluid Flow Model}

1) Laminar Flow

The fluid is indicated by the motion of the fluid particles parallel and the flow lines are smooth. In laminar flow, fluid particles seem to move along smooth and smooth paths, with one layer gliding smoothly on adjacent layers. The nature of the viscosity of liquid plays an important role in the formation of laminar flow. Laminary flow is steady, indicating that in all water flows, the flow rate is constant or the flow rate does not change with time as shown in Figure 2 [2].

2) Turbulent Flow
A relatively large flow velocity will produce a flow that is not laminar but complex, the path of motion of these particles is mutually irregular with each other. So that turbulent flow characteristics are obtained: there is no regularity in the fluid path, mixed flow, high fluid velocity, large scale length, and low viscosity as shown in Figure 3. What distinguishes turbulent or laminar flow, there is a non-unified number called Reynold Number. This number is calculated by the equation as follows [2]:

$\mathrm{Rn}=\frac{L V}{v}$

Where:

$\mathrm{V}$ : flow speed $\quad(\mathrm{m} / \mathrm{s})$

$\checkmark$ : kinematic viscosity of water at a standard temperature of $\quad 15 \quad{ }^{\circ} \mathrm{C}$.

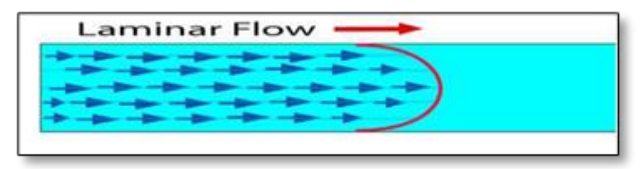

Figure. 2. Laminar flow

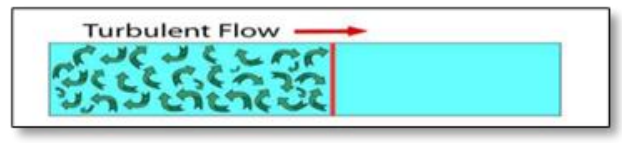

Figure. 3. Turbulent flow.

\section{The Phenomenon of the Flow of Water Behind the Ship}

Wake is the interaction between a ship and water which has a relative speed to the ship. Wake is divided into three parts: the speed of water around the ship's body, the water layer between the water flow resistance around the ship's body, the waves formed by the movement of the ship in the water. The phenomenon that occurs in the behind of the ship due to changes in the speed of flow generated from the front of the ship. The flow of water that will enter the propeller has an impact on the efficiency of propulsion.

The bigger $\mathrm{w}$ that occurs will result in $\mathrm{Va}$ will be smaller. With Va getting smaller, the power needed to push the ship to reach the desired speed will be greater. The effective wake speed on this propeller is $\mathrm{Vw}$, which has a direction equal to the speed of ship $\mathrm{V}$, so that the speed of water that reaches the propeller, Va (speed of advance of propeller), the average velocity of the propeller disk $\mathrm{Vw}$, is lower than the speed ship $\mathrm{V}$. Effective wake speed on propeller: $\mathrm{Vw}=\mathrm{V}-\mathrm{Va}$, the 
wake fraction parameter coefficient is defined by Taylor as follows:

$$
\begin{array}{lll}
\frac{V a}{V s}=(1-w) & \\
\text { Va } & : \text { velocity od advance } & (\mathrm{m} / \mathrm{s}) \\
\text { Vs } & : \text { speed of ship } & (\mathrm{m} / \mathrm{s}) \\
\mathrm{W} & : \text { wake friction } &
\end{array}
$$

The wake coefficient of this fraction depends on the shape of the ship body, also the location or placement, and the dimensions of the propeller, this has a lot of influence on propeller efficiency. Propeller diameter or comparison between propeller diameter and vessel length [3].

\section{Resistance of Ship}

The resistance of the ship at a speed is the force of the fluid acting on the vessel in such a way that it opposes the movement of the vessel. The resistance is the same as the component of the fluid force acting parallel to the axis of the ship's movement. The amount of resistance will affect the speed and power requirements of the ship's crankcase. Total resistance (Rt) of the ship consists of several components and is the sum of several components of resistance $\mathrm{Rt}=$ Rfriction + Rwave + Rair + Raddition.

1) Friction Resistance

Friction resistance is a component of the resistance obtained by neutralizing the tangential voltage to the entire wet surface of the vessel according to the direction of movement of the ship. All fluids have viscosity, and this viscosity causes friction. The importance of this friction in a physical situation depends on the type of fluid and its physical configuration or flow pattern [4].

$$
\mathrm{Cf}=\frac{0,075}{(\log 10 R n-2)^{2}}[\text { [5] }
$$

Where:

$$
\begin{aligned}
& \mathrm{L} \quad \text { : lenght of ship (m) } \\
& \mathrm{Rn} \quad \text { : reynold number } \\
& \mathrm{RF}=1 / 2 . \rho \times \mathrm{Cf} \times \mathrm{S} \times \mathrm{Vs}^{2} \\
& \text { Where: }
\end{aligned}
$$$$
\rho \quad \text { : density of sea water }
$$$$
\mathrm{Cf} \text { : friction resistance coefficient }
$$$$
\mathrm{S} \quad \text { : wet surface area }
$$$$
\text { Vs : ship speed }
$$

\section{2) Wave Resistance}

Wave resistance is an obstacle caused by the shape of the body of the hull and the movement of the vessel in the water so that it can cause waves either when the water is calm or when the water is surging. [4]

$$
\begin{aligned}
& \mathrm{RW}=1 / 2 . \rho \times \mathrm{CW} \times \mathrm{S} \times \mathrm{Vs}^{2} \\
& \text { Where: } \\
& \rho \quad \text { : density of seawater } \\
& \mathrm{CW} \quad \text { : wave resistance coefficient } \\
& \mathrm{S} \quad \text { : wet surface area } \\
& \mathrm{Vs} \quad \text { : ship speed }
\end{aligned}
$$

\section{3) Air Resistance}

Air resistance is defined as a resistance experienced by the main body part of the ship that is above the water and the upper building (Superstructure) because of the movement of the ship in the air. This prisoner depends on the speed of the ship and the area and shape of the building. If the wind blows, the prisoner will also depend on the wind speed and the relative direction of the wind on the ship [4].

$\mathrm{Ra}=1 / 2 . \rho \times \mathrm{Caa} \times \mathrm{S} \times \mathrm{Vs}^{2}$

Where:

$\rho \quad$ : density of sea water

Caa : air resistance coefficient

$\mathrm{S}$ : wet surface area

$\left(\mathrm{kg} / \mathrm{m}^{3}\right)$

Vs : ship speed

\section{E. Power Distribution of Ship}

\section{1) Effective Horsepower}

Effective horsepower is the amount of power needed to overcome the drag force of the ship's body, so the ship can move from one place to another with a service speed of Vs. This effective power is a function of the amount of total drag and speed of the ship. [6]

$\mathrm{EHP}=\mathrm{R}_{\text {Tservice }} \mathrm{x} \mathrm{Vs}$

Where:

$\begin{array}{lll}\text { EHP } & : \text { Effective horsepower } & (\mathrm{HP}) \\ \mathrm{R}_{\text {Tservice }} & : \text { Resistance of ship } & (\mathrm{kN}) \\ \mathrm{Vs} & : \text { Speed service } & (\mathrm{knot})\end{array}$

2) Delivered Horsepower

A power that is absorbed by the ship's propeller to produce thrust or power that is channeled by the motor to the propeller of the ship which is then converted into the thrust of the ship. [6]

$\mathrm{DHP}=\frac{E H P}{P C}$

Where:

DHP : Delivered horsepower (HP)

EHP : Effective horsepower

PC : Coeffisien propulsive

\section{3) Thrust Horsepower}

When the ship moves forward, the propeller will accelerate with water. This acceleration will increase the momentum of the water. Based on Newton's second law, force is equivalent to the acceleration rank of the momentum of water, called thurst [6].

$\mathrm{THP}=\frac{E H P}{\eta_{H}}$

Where:

THP : Thrust horsepower

EHP : Effective horsepower

$\eta_{\mathrm{H}} \quad$ : Efficiency hull

\section{4) Shaft Horsepower}

For ships whose engine rooms are located at the rear, there will be losses of $2 \%$, while for ships whose engine rooms in the midship area of the ship experience losses of $3 \%$. In this plan, the engine room is located at the back, so that losses occur only $\eta \mathrm{S}=0.98$ [7]. 


$$
\mathrm{SHP}=\frac{D H P}{\eta_{S}}
$$

Where:

$\begin{array}{ll}\text { SHP } & : \text { Shaft horsepower } \\ \text { DHP } & : \text { Delivered horsepower } \\ \eta_{S} & : \text { Efficiency shaft }\end{array}$

5) Brake Horsepower

BHP (Brake Horsepower) is the power produced by the main propulsion of the ship. The main propulsion of the ship is a part of the driving system that converts heat energy to mechanical energy (rotation). [6] BHP-SCR is the output power of the driving motor in continuous service rating (SCR) conditions, namely motor power in conditions of $80-85 \%$ of maximum continuous rating (MCR) [6].

$\mathrm{BHP}=\frac{S H P}{\eta_{G}}$

Where:

BHP

SHP : : Shaft horsepower

$\eta_{\mathrm{G}} \quad$ : Efficiency gearbox

\section{F. Hull and Propeller Characteristic}

1) Characteristic of Propeller

A propeller is a tool that can be used to move the ship from one place to another. In other words, it can be concluded that a commonly used propeller for utilization in power plants such as windmills and also can be used for thrust, propeller also has some leaves [8]. In general, the characteristics of ship propellers in open water test conditions are as represented in the KT-KQ-J Diagram as in Figure 4. Each type of ship propeller has different performance curve characteristics. So that the study of the characteristics of the propellers cannot be generalized to the overall shape or type of propellers. The equation model for the performance characteristics of ship propellers is as follows [9]:

$$
\begin{aligned}
& \mathrm{KT}=\frac{\mathrm{TProp}}{\rho \times \mathrm{n}^{2} \times D^{4}} \\
& \mathrm{KQ}=\frac{\mathrm{QProp}}{\rho \times \mathrm{n}^{2} \times D^{5}} \\
& \eta_{\mathrm{o}}=\frac{\mathrm{J} \times \mathrm{KT}}{2 \pi \times \mathrm{KQ}}
\end{aligned}
$$

Where:

KT : propeller thrust coefficient

KQ : propeller torque coefficient

J : Advance velocity coefficient

по : propeller efficiency in open water conditions

$\mathrm{Va}$ : advance velocity (m/s)

$\mathrm{n} \quad$ : revolution per second (rps)

D : propeller diameter (m)

$\mathrm{T}$ : propeller thrust $(\mathrm{kN})$

$\mathrm{Q}$ : propeller torque (kN.m)

$\rho \quad$ : fluid density $\quad\left(\mathrm{kg} / \mathrm{m}^{3}\right)$

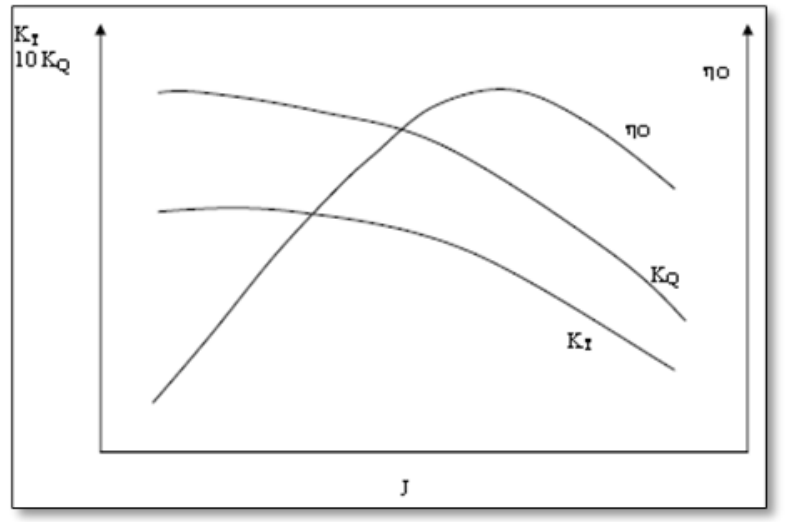

Figure. 4. Open Water Test (KT-KQ and J) diagram.

2) Hull and Propeller Interaction

Hull \& Propeller Interaction interaction is an approach on paper to obtain the performance characteristics of propellers when operating for conditions behind the ship, as follows:

$$
\begin{aligned}
\mathrm{T}_{\text {Ship }} & =\frac{\alpha \times V a^{2}}{(1-\mathrm{t})(1-\mathrm{w})^{2}} \\
\mathrm{~T}_{\text {Prop }} & =\mathrm{KT} \times \rho \times \mathrm{n}^{2} \times \mathrm{D}^{4} \\
\mathrm{KT} & =\frac{\alpha \times V a^{2}}{(1-\mathrm{t})(1-\mathrm{w})^{2} \times \rho \times \mathrm{n}^{2} \times \mathrm{D}^{4}} \\
\mathrm{~B} & =\frac{\alpha}{(1-\mathrm{t})(1-\mathrm{w})^{2} \times \rho \times \mathrm{D}^{2}} \\
\mathrm{KT} & =ß \times \frac{V a^{2}}{\mathrm{n}^{2} \times \mathrm{D}^{2}}
\end{aligned}
$$

So that the equation relationship is obtained, as follows:

$\mathrm{KT}=\quad 3 \times \mathrm{J}^{2}$

In Figure 5. there is an interactive form of the propeller performance in the condition behind the ship body, which at the 1st Curve is the propeller thrust coefficient trendline for trial conditions. And by looking at the condition of Curve $\mathrm{J} 3$, the price of the propeller torque coefficient, KQ is obtained in the trial condition. Whereas Curve 2 is the trendline of propeller thrust coefficient in hull service margin conditions and by drawing the $\mathrm{J} 4$ curve so that it passes the KT-SM point, then the propeller torque coefficient, KQ-SM, is obtained under hull service 
margin conditions. Furthermore, these two KQ and KQ-SM numbers are used to determine propeller load characteristics (propeller load characteristics) as in Figure 5 [9].

The study of propeller-hull interaction is important to predict the efficiency of the propeller as well as its influences on the resistance of the ship hull. By the Computational Fluid Dynamics (CFD) method, the viscous flow computation of the ship hull is normally coupled with some propeller programs either by viscous method or by the potential method. In the viscous model, the propeller, hull, and rudder geometries are all resolved directly in the RANS grid in which the solid bodies are considered as no-slip faces and all of these become parts of the viscous flow solution [10].

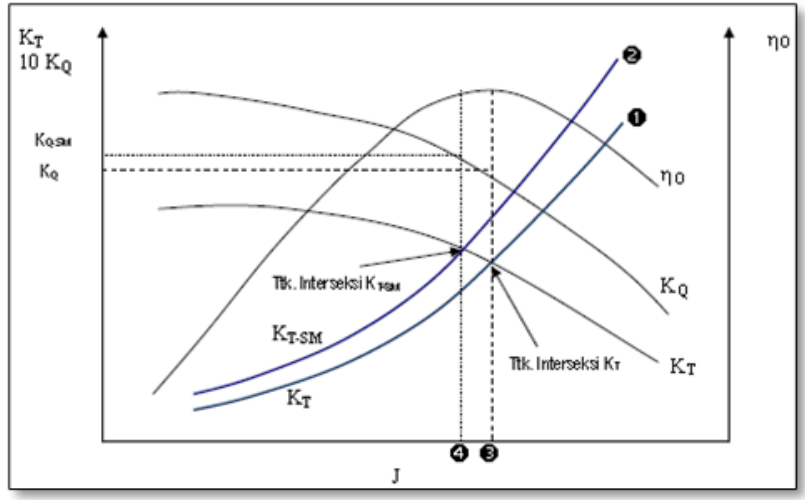

Figure. 5. Plotting KT \& KT-SM on the Open Water Test curve.

\section{G. Computational Fluid Dyanamic-Actuator Disk Propeller}

The simplest possible idealization of a propeller is by treating the propeller as an actuator disk. That is, the physical propeller is replaced by a permeable disk of equal radius. The actuator disk causes an instantaneous uniform pressure jump in the fluid, which can be related to the change in the fluid velocity within the slipstream. The thrust, torque, and delivered power can be attributed to this change in fluid velocity. The method can be useful for maximum efficiency calculations as well as an estimate for the propeller-induced velocity. In addition, the computational speed is superior to other methods. However, momentum theory does not provide any information on the differential propeller thrust and torque at a given blade section. Thus it is considered too simple.
The CFD-ADM is a commonly employed analysis method that provides the solution of the Navier-Stokes or Euler equations in a domain comprising a propeller represented through a body force distribution acting over a disc area. From a computational point of view, these distributions are obtained by pursuing several approaches, such as iterative and interactive coupling with lifting-surface, boundary element, or blade element methods [11].

The integration of forces inside the propeller radius gives thrust $(\mathrm{T})$ and torque $(\mathrm{Q})$ to the propeller. When the propeller is rotating, with effective inflow velocity, there will be an induced velocity by the propeller and the RANS computation with body force distribution can give the resultant axial velocity component and the propeller model is running based on this value.

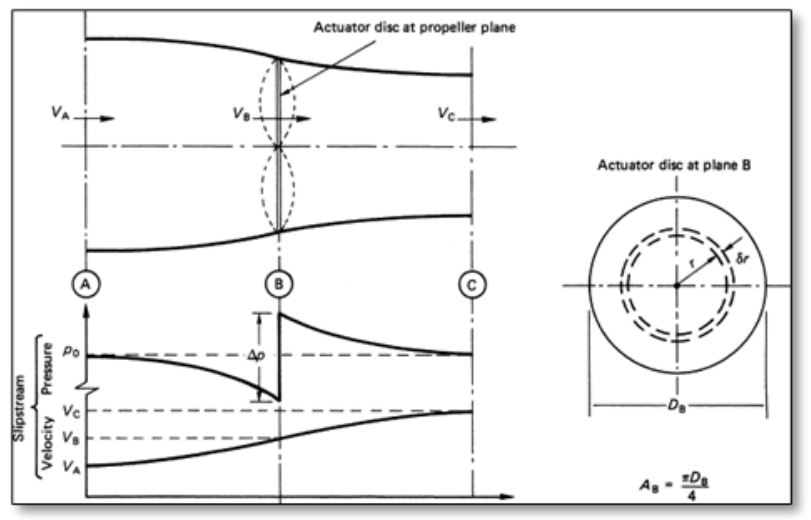

Figure. 6. Actuator disk propeller theory.

Figure 6. illustrates the change in flow in the annular tube as it passes through the propeller disk actuator and there is an increase in pressure due to the emergence of fluid flow passing through the disk actuator. Flow considerations along with the annular radius $\mathrm{r}$ and $\delta \mathrm{r}$ thickness on the propeller disk. Encouragement and torque can be obtained from changes in momentum that occur in the flow of fluid in the lower part of the annular tube. This simple conclusion drawn out of the simplified flow model permits design, analysis, and even 
experimental verification of the propeller performance rather quickly. Thus, thrust [12]:

$\mathrm{T}=1 / 2 \times \rho \times \mathrm{A}\left(\mathrm{VC}^{2}-\mathrm{VA}^{2}\right)$

The propeller disk actuator calculation process uses the momentum propeller theory equation which is used to model the propeller effect without modeling a real propeller. The approach in calculating fb (tangential) includes the simple distribution specified, which is used in determining the total thrust $\mathrm{T}$ and torque $\mathrm{Q}$, the interaction between the propeller and the hull of the ship. Where the calculation uses the propeller performance code interactively with the theory of RANS solvers to capture the propeller interaction with the hull of the ship and to distribute the $\mathrm{fb}$ according to the actual blade. But ISIS-CFD includes body strength determined by axial and tangential components [13].

$\mathrm{f}_{\mathrm{bx}}=\mathrm{A}_{\mathrm{x}} r^{*} \sqrt{1-r^{*}}, \mathrm{f}_{\mathrm{b} \theta}=\mathrm{A}_{\theta} \frac{r^{*} \sqrt{1-r^{*}}}{r^{*}\left(1-r_{h}^{l}\right)}$

Actuator disk propellers represent body strength per unit volume normalized by, where $U$ is the reference speed, $\mathrm{L}$ is the reference length and $\rho$ is the fluid density. The coefficient is stated as follows:

$r^{*}=\frac{r^{\prime}-r_{h}^{l}}{1-r_{h}^{l}}, \quad r_{h}^{\prime}=\frac{R_{H}}{R_{P}}, \quad r^{r}=\frac{r}{R_{P}}$

$r=\sqrt{(y-Y p c)^{2}+(z-Z p c)^{2}}$

$A_{x}=\frac{C_{T}}{\Delta} x \frac{105}{16\left(4+3 r_{h}^{l}\right)\left(1-r_{h}^{\prime}\right)}$

$A_{\theta}=\frac{K_{Q}}{\Delta J^{2}} x \frac{105}{\pi\left(4+3 r_{h}^{l}\right)\left(1-r_{h}^{l}\right)}$

$J=\frac{2 \pi U}{\Omega D p}=\frac{U}{\Omega D p}, I=2 R_{P}, n=\frac{\Omega}{2 \pi}$

$C_{T}=\frac{2 T}{\rho U^{2} \pi R_{P}^{2}}, K_{T}=\frac{T}{\rho n^{2} D_{P}^{4}}, K_{Q}=\frac{Q}{\rho n^{2} D_{P}^{5}}$

where $C_{T}$ and $K_{Q}$ are the thrust and torque coefficients, J is the advance coefficient, $\mathrm{n}$ is the number of rotations per second (rps), $\Omega$ is the rotation speed, $R_{P}$ is the propeller radius, $R_{H}$ is the hub radius, $\Delta$ is the mean chord length projected into the $\mathrm{x}-\mathrm{Z}$ plane (or actuator disc thickness), and $Y p c Z p c$ define the propeller center coordinates. Variable $r$ is the normalized distance to a propeller in the propeller plane. As derived, these forces are defined over an actuator disk with the volume defined by $R_{P}, R_{H}$ and $\Delta$.

In ISIS-CFD, there is no need to specify, and $\mathrm{J}$, but the thrust $\mathrm{T}$ and the torque $\mathrm{Q}$ are prescribed. The coefficients and are then computing using the above relations [14].

\section{RESULT AND DISCUSSION \\ A. Geometry and Cond [ition}

Specification data MV. Mina Makmur 150 GT gillnet fishing vessel includes the main sizes of ships and engines. The following is a description of the specification data on a 150 GT fishing vessel:

1) The main dimension of the ship

$\begin{array}{llc}\text { Name of ship } & : \text { MV. Kelola Mina Makmur } \\ \text { Loa } & : 27.3 & \mathrm{~m} \\ \text { Lpp } & : 24 & \mathrm{~m} \\ \mathrm{~B} & : 8 & \mathrm{~m} \\ \text { Hhull } & : 3 & \mathrm{~m} \\ \mathrm{~T} & : 1.8 & \mathrm{~m} \\ \mathrm{Cb} & : 0.581 & \\ \mathrm{Cm} & : 0.905 & \\ \mathrm{Cwp} & : 0.804 & \\ \mathrm{Cp} & : 0.644 & \\ \text { Vs } & : 7.821 & \text { knot } \\ \mathrm{GT} & : 150 \mathrm{GT} & \end{array}$

2) Specification of Engine

$\begin{array}{lll}\text { Engine Brand } & : \text { Mitsubishi Marine Engines } \\ \text { Power } & : 657 & \text { HP } \\ \text { Engine Speed } & : 1960 & \text { rpm }\end{array}$

3) Specification Propeller

Propeller data is obtained from (NMRI, 2015) as an igs file together with offset data of propeller. [13]

Propeller No. $\quad$ : NMRI

Type : Fixed Pitch

No. Blades $\quad: 5$

Diameter : $1.052 \quad \mathrm{~m}$

$\begin{array}{ll}\text { Rotation } & : \text { Clockwise } \\ \text { Pitch (constant) } & : 0.15225 \quad \mathrm{~m}\end{array}$

Expanded area ratio : 0.5

Blade thickness ratio : 0.05

\section{B. Model of Ship}

Model making is done using Maxsurf software and Rhinoceros software. In addition, Rhinoceros is used to change the shape of the surface so that it can be moved in the Parasolid "x_t" format. The scheme of the model making process as Figure 7, is as follows:

TABEL 1.

OFFSIDE OF EXSISTING MV. MINA MAKMUR $150 \mathrm{GT}$

\begin{tabular}{c|ccccccccc}
\hline ST / WL & WL 0 & WL 0.5 & WL 1 & WL 1.5 & WL 2 & WL 2.5 & WL 3 & WL 3.5 & WL 5.66 \\
\hline ST -3 & 0 & 0 & 0 & 0 & 0 & 0 & 4.068 & 4.059 & 4.087 \\
ST -2 & 0 & 0 & 0 & 0 & 0 & 0 & 4.112 & 4.161 & 4.19 \\
ST - 1 & 0 & 0 & 0 & 0 & 0 & 0 & 4.263 & 4.307 & 4.289 \\
ST 0 & 0 & 0 & 0 & 0 & 4.012 & 4.159 & 4.189 & 4.338 & 0 \\
ST 1 & 0 & 0 & 0 & 4.15 & 4.142 & 4.247 & 4.381 & 4.332 & 0 \\
ST 2 & 0 & 0 & 3.955 & 4.109 & 4.413 & 4.487 & 4.539 & 4.596 & 0 \\
ST 3 & 0 & 3.689 & 4.001 & 4.107 & 4.205 & 4.252 & 4.312 & 4.6 & 0
\end{tabular}




\begin{tabular}{l|lllllllll} 
ST 4 & 0 & 3.653 & 3.946 & 4.084 & 4.103 & 4.216 & 4.274 & 4.6 & 0 \\
ST 5 & 0 & 3.289 & 3.849 & 4.007 & 4.069 & 4.129 & 4.189 & 4.6 & 0 \\
ST 6 & 0 & 3.398 & 3.62 & 3.794 & 3.924 & 3.978 & 4.125 & 4.6 & 0 \\
ST 7 & 0 & 1.604 & 2.414 & 3.057 & 3.306 & 3.488 & 3.655 & 3.776 & 0 \\
ST 8 & 0 & 1.604 & 1.231 & 1.812 & 2.302 & 2.454 & 2.776 & 3.129 & 0 \\
\hline
\end{tabular}

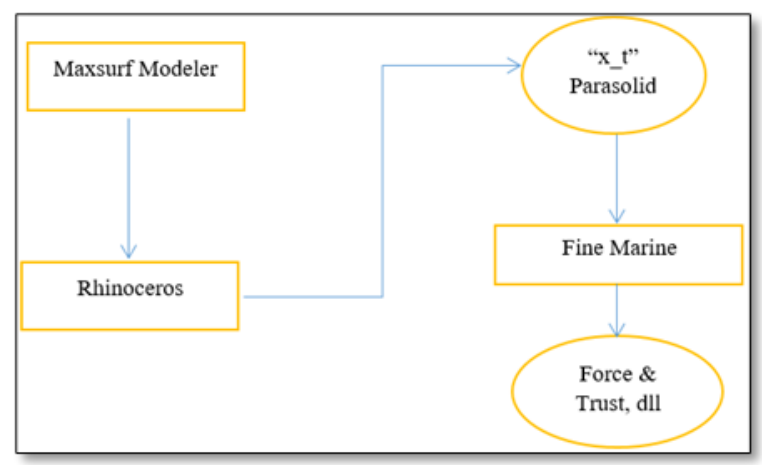

Figure. 7. Scheme of the Numeca Fine Marine testing process.

\section{Simulation Process Using CFD software}

CFD is a numerical analysis method used to solve fluid dynamics problems. Since the great advances in computer performance, the CFD method is used to solve the Reynolds Averaged Navier-Stokes (RANS) equations that have been applied to different types of stern there are several processes performed in the CFD method. As for the process in CFD, there are 3 parts:

1) Pre-Processor
The initial stage in Computational Fluid Dynamic (CFD) is the stage of data input that includes the determination of domain and boundary conditions. At this stage, meshing is also done, where the analyzed object is divided in the number of specific grids as in figure 8. Meshing on Numeca fine marine 7.1 can be done automatically by using $\mathrm{C}$-wizard. In the $\mathrm{C}$-wizard, it will be easy to make domain settings, where domains that are used to conduct prisoner testing from the use of C-wizards will automatically form domain boxes based on ITTC standards.

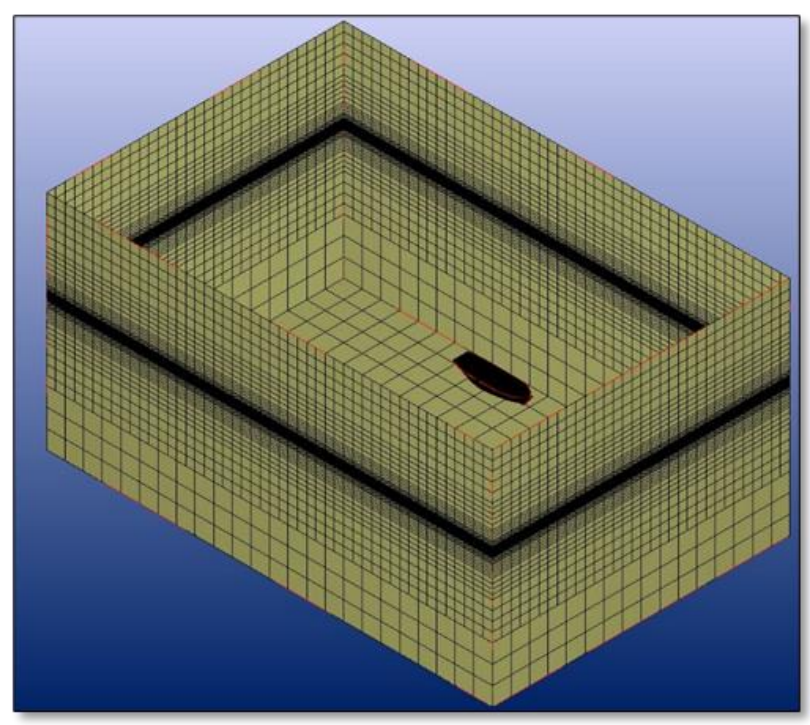

Figure. 8. The results of meshing. 


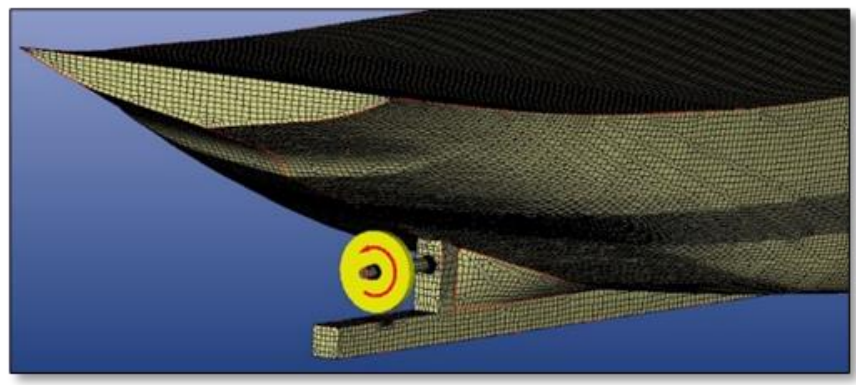

Figure. 9. The results of meshing with actuator disk.

From the results of all stages of the meshing, the number of cells that will be used in the running or solver stage will be obtained, the greater the number of cells produced will be the longer the running time. From the results of meshing the number of cells is obtained, as follows:

$\mathrm{Nb}$ of cells $\quad=3175811 / 3175811$

$\mathrm{Nb}$ of verticals $=3336429 / 3336429$

2) Processor

The next stage is stage processor, where at this stage is done data calculation process that has been entered using related equation iteratively until the results obtained can reach the smallest error value [16].
3) PostProcessor

The last stage is the post-processor stage, the results of the calculations at the stage of the processor will be displayed in pictures, graphics, and animations [16].

III.4 The Result Configuration Clearance of Propeller

To find out how much the thrust and speed of the ship is clearance actuator disk propeller, the propulsion system configuration plays an important role. Figure 10 displays a configuration model for laying clearance actuator propeller disk used on 150 GT fishing vessels by reference to the point of the steering shaft of the ship as in figure 9. Here are the results:

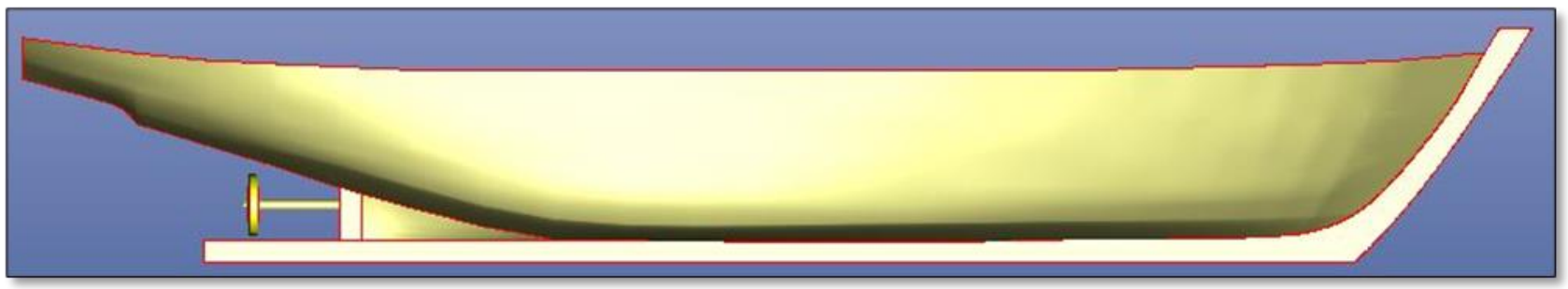

(A)

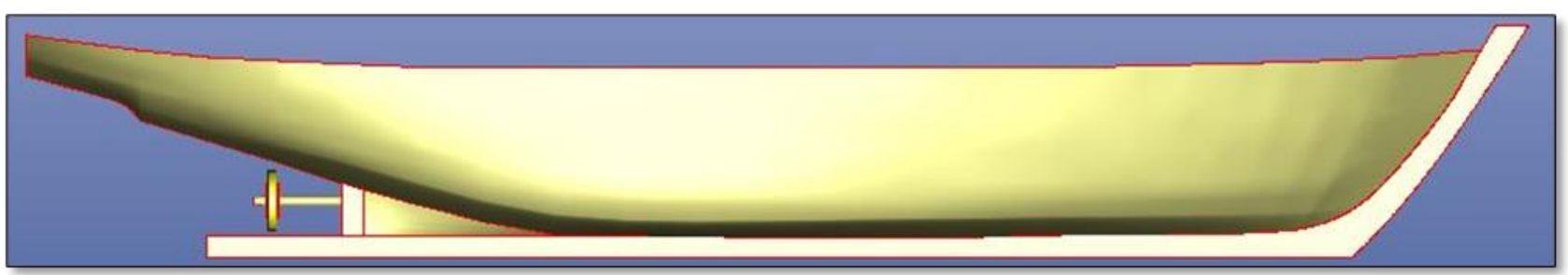

(B)

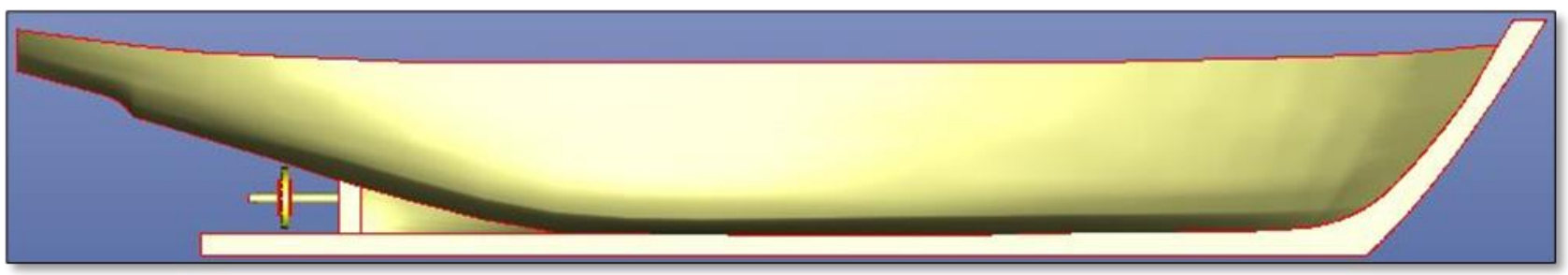

(C)

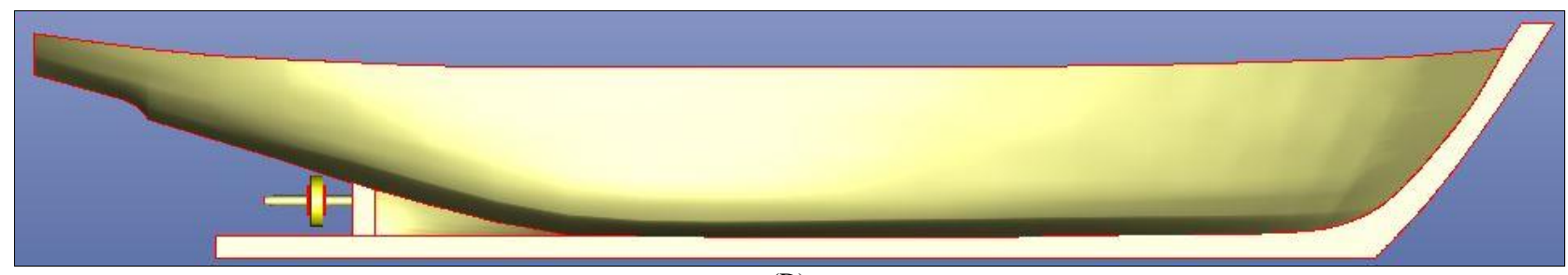

(D)

Figure 10. Variation in the configuration of actuator disk propeller 
THE RESULTS OF CONFIGURATION CLEARANCE OF ACTUATOR DISK PROPELLER

\begin{tabular}{cccccc}
\hline No & Propeller Clearance & D Prop $(\mathrm{m})$ & $\mathrm{T}(\mathrm{N})$ & $\mathrm{Q}(\mathrm{N} . \mathrm{m})$ & $\mathrm{n}(\mathrm{rps})$ \\
\hline 1 & -0.162 & 1.052 & 46948.83 & 5097.06 & 17.09 \\
2 & 0.138 & 1.052 & 39575.64 & 5266.05 & 11.41 \\
3 & 0.438 & 1.052 & 32139.26 & 4411.46 & 10.75 \\
4 & 0.738 & 0.88 & 37715.34 & 5153.68 & 11.67 \\
\hline
\end{tabular}

TABEL 3.

THE RESULTS OF PROPULSION EFFICIENCY FROM CONFIGURATION CLEARANCE OF ACTUATOR DISK PROPELLER

\begin{tabular}{ccccccc}
\hline No & Propeller Clearance & D Prop $(\mathrm{m})$ & KT & KQ & J & $\eta$ Prop \\
\hline 1 & -0.162 & 1.052 & 0.26 & 0.032 & 0.29 & 0.37 \\
2 & 0.138 & 1.052 & 0.24 & 0.030 & 0.34 & 0.43 \\
3 & 0.438 & 1.052 & 0.22 & 0.028 & 0.39 & 0.48 \\
4 & 0.738 & 0.88 & 0.22 & 0.028 & 0.40 & 0.50 \\
\hline
\end{tabular}

From the analysis, in Table 2 the highest thrust, torque, and rotation parameters are obtained in "Configuration A" with the propeller clearance $-0.162 \mathrm{~m}$. These parameters tend to decrease when the clearance actuator disk propeller knows the hull of the ship. Reduced on clearance actuator disk propeller between $0.138 \mathrm{~m} \mathrm{-}$ $0.738 \mathrm{~m}$ from the steering shaft can be caused by the slope angle formed between the water with the stern longitudinal hull (skeg) section that exceeds the required conditions thus the flow of water passing through the propeller is not sufficient propeller work. But high thrust, torque, and rotation do not necessarily have a high level of efficiency because the rise or fall of thrust, torque, and rotation will affect the efficiency of propulsion. The parameters of thrust, torque, and advance velocity have coefficients that are useful for finding the efficiency of propulsion. Where the basic formula for propulsion efficiency is $\eta \mathrm{O}=\frac{\mathrm{J} \times \mathrm{KT}}{2 \pi \times \mathrm{KQ}}$. The coefficient is also depicted on the graph $\mathrm{KT}, \mathrm{KQ}$, and $\mathrm{J}$ on the selected propeller. So that in addition to the thrust, torque, and rotation parameters must also be determined also the value of high propulsion efficiency in order to get a match between the hull and the propeller laying. From Table 3 and Figure 11 the highest propulsion efficiency is obtained in "Configuration $\mathrm{D}$ " with the placement distance of propeller disk actuator $0.738 \mathrm{~m}$. This happens because the propeller with the hull has a match so that it has an impact on the flow of water passing through the high propeller as the propeller works.

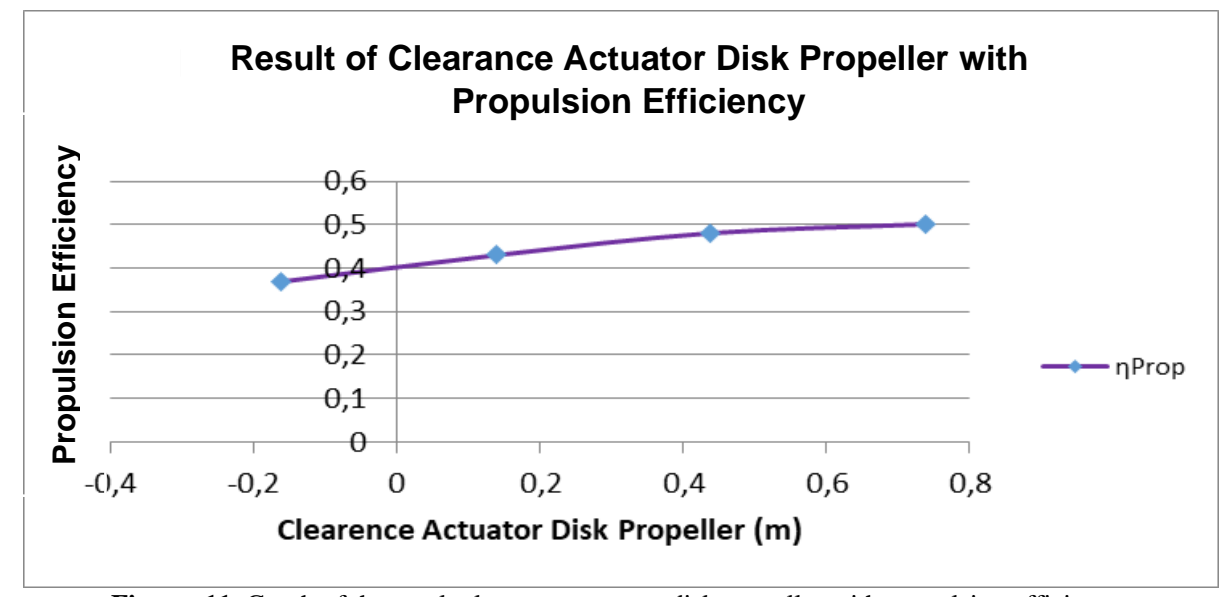

Figure. 11. Graph of the result clearance actuator disk propeller with propulsion efficiency.

\section{E. Visualization and Results Simulation on CFView}

From the results of the simulation process, get the flow parameters around the propeller that are displayed using CFView. To know the interaction of the flow between the hull of the ship and propeller placement. Computing from advance velocity is represented in the form of an actuator disk propeller. The next step is to take a visual sample of the variation of the propeller disk actuator as follows: 


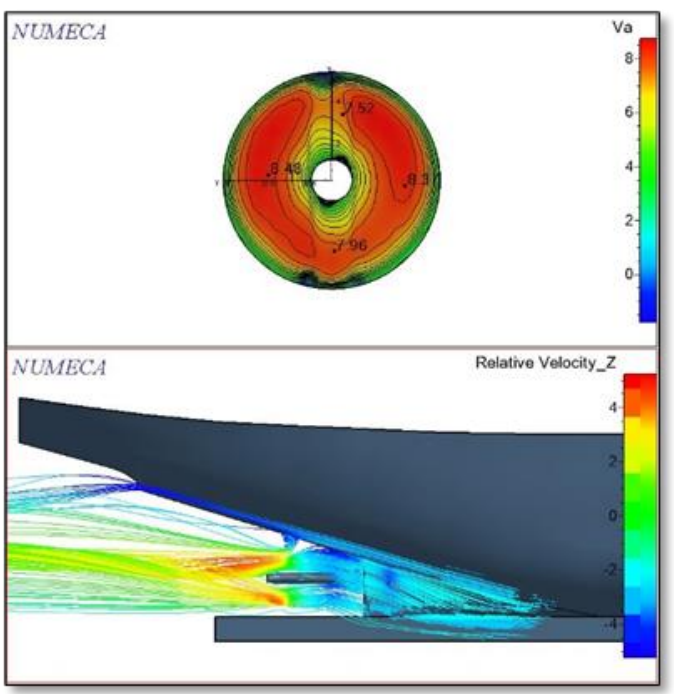

(a)

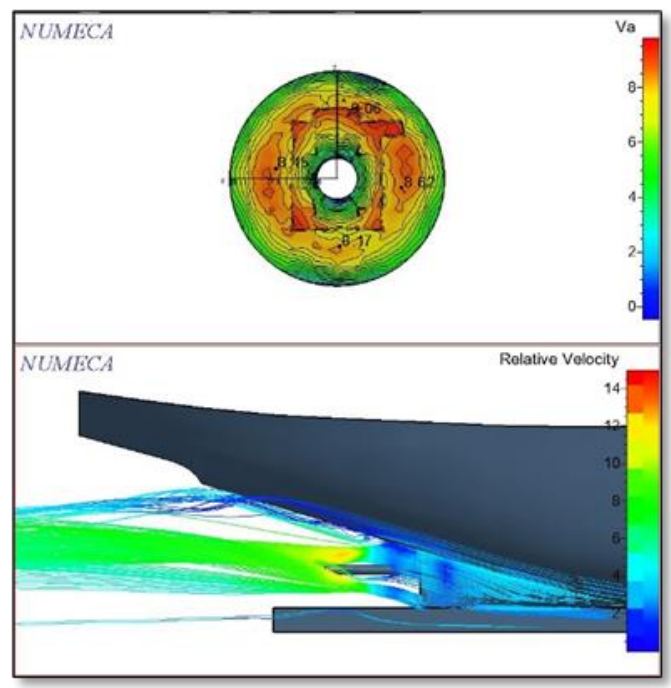

(c)

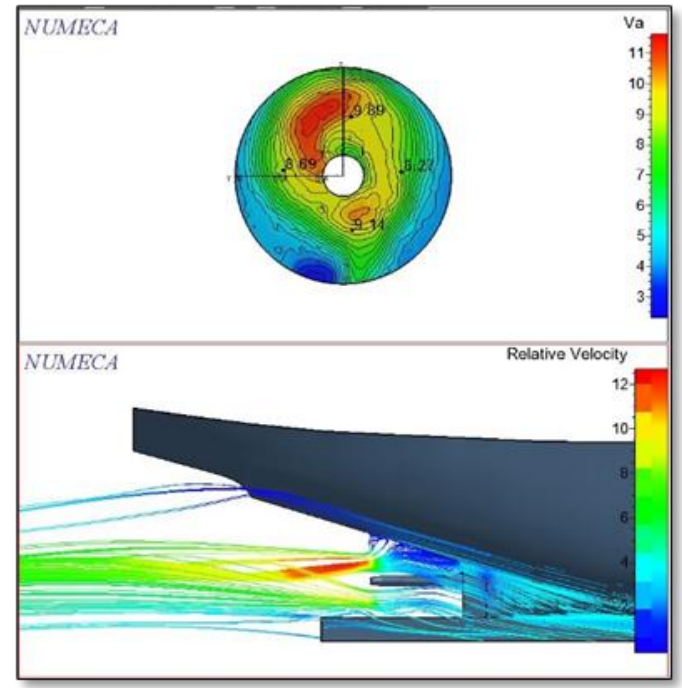

(b)

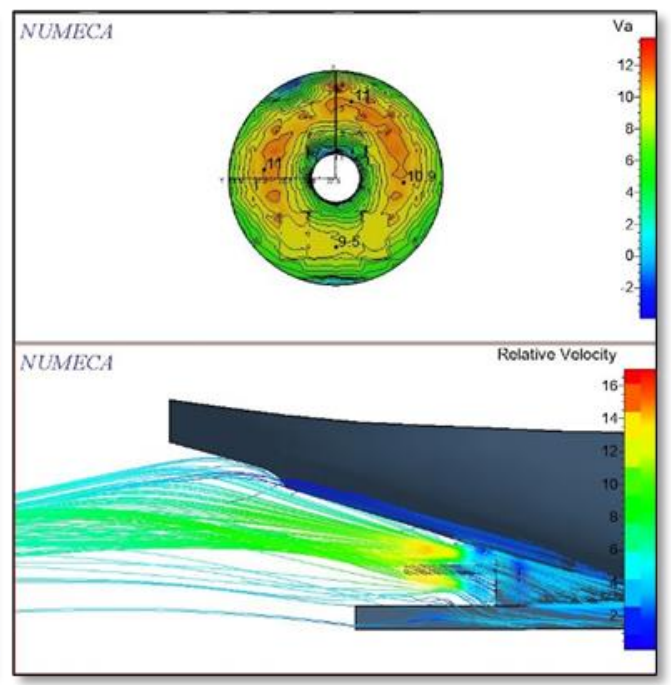

(d)

Figure. 12. CFView results of wave flow analysis on the actuator disk propeller.

TABEL 4.

THE RESULTS ADVANCE VELOCITY OF CONFIGURING CLEARANCE OF ACTUATOR DISK PROPELLER

\begin{tabular}{ccc}
\hline No & Propeller Clearance & Va (knot) \\
\hline 1 & -0.162 & 8 \\
2 & 0.138 & 8.5 \\
3 & 0.438 & 8.6 \\
4 & 0.738 & 10.6
\end{tabular}

The result of the speed of the water flow that reaches the propeller is the advance velocity in Tabel 4 Homogeneous wake flow around the propeller can increase advance velocity and result in an increase in service speed, where the wave flow relationship, advance velocity, and service speed have a formula $\mathrm{Vs}=\frac{\mathrm{Va}}{(1-\mathrm{w})}$. From Figure 15 it can be analyzed that the most optimal movement is at a distance of $0.738 \mathrm{~m}$ in figure (d), because the flow passing through the propeller disk actuator is large and homogeneous. While the configurations (a), (b), and (c) flow through the actuator disk propellers are low because of the slope angle formed between the water and the stern longitudinal axis of the ship hull (skeg) which exceeds the required conditions thus the flow of water passing through propeller is not sufficient as a propeller work [17]. 


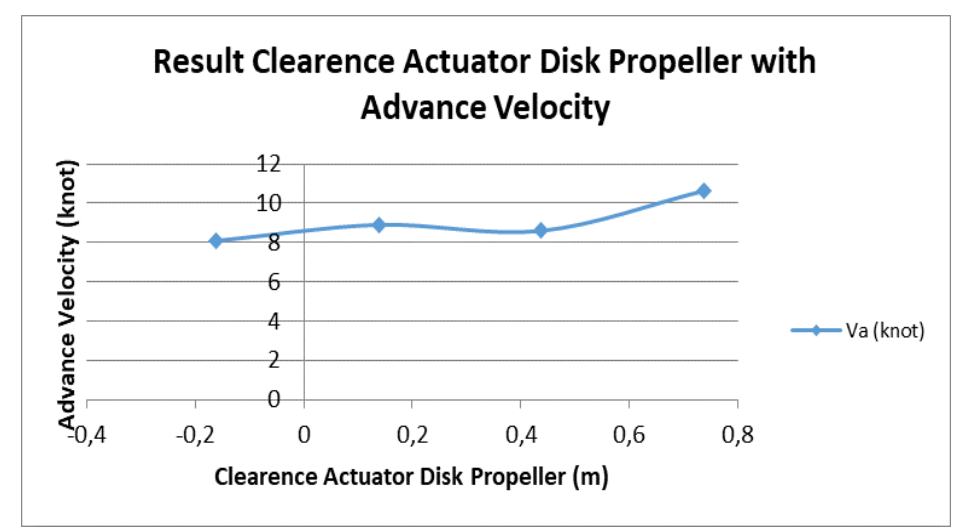

Figure. 16. Graph of the result clearance actuator disk propeller with advance velocity.

From the results of the analysis in Figure 16 the highest advance velocity was obtained at the laying distance of the propeller disk actuator $0.738 \mathrm{~m}$ with a value of 10.6 knots. So that it can be concluded that the addition of the laying distance of the propeller disk actuator can cause an increase in the advance velocity that passes through the propeller thus impacting the efficiency of propulsion, where the basic formula is $\eta_{\mathrm{o}}$ $=\frac{\mathrm{J} \times \mathrm{KT}}{2 \pi \times \mathrm{KQ}} . \mathrm{J}$ is the advance velocity coefficient so that with an increase in $\mathbf{J}$ it will have an impact on the increase in propulsion efficiency. Finally, the simulation service speed will increase according to the initial goal.

\section{F. Calculation of Power Requirement}

1) Thrust Horsepower

The thrust obtained from the simulation results is 37715.24 N. The thrust produced is as follows:

$$
\begin{array}{rlr}
\text { THP } & =\text { F x Vs } \\
& =37715.24 \times 5.14444 \\
& =194.03 \quad \mathrm{~kW}
\end{array}
$$

2) Coefficient Propulsive

The propulsive coefficient is the multiplication of hull efficiency, propeller efficiency and relative rotative efficiency, as follows:

$$
\begin{aligned}
\mathrm{Pc} & =\eta \mathrm{H} \times \eta \mathrm{rr} \times \eta 0 \\
& =1 \times 1.05 \times 0.5 \\
& =0.525
\end{aligned}
$$

3) Effective Horsepower

Effective horsepower is the amount of power needed to overcome the drag force of the ship's body, so the ship can move from one place to another with a service speed of Vs.

$$
\begin{aligned}
\mathrm{EHP} & =\mathrm{THP} \times \eta_{\mathrm{H}} \\
& =194.03 \times 1 \\
& =194.03
\end{aligned}
$$

So that from this value the ship detention is as follows:

$$
\begin{aligned}
\mathrm{R}_{\text {Tdinas }} & =\frac{E H P}{V_{g}} \\
& =\frac{194.03}{5.14444} \\
& =37716
\end{aligned}
$$

4) Delivered Horsepower

So that the power in the propeller shaft tube is calculated from the calculation of the effective power with the propulsion coefficient, Delivered Horsepower (DHP), is as follows:

$$
\begin{aligned}
\mathrm{DHP} & =\frac{E H P}{P c} \\
& =\frac{194.03}{0.525} \\
& =369.6 \quad \mathrm{~kW}
\end{aligned}
$$

\section{5) Shaft Horsepower}

For ships whose engine rooms are located at the rear, there will be losses of $2 \%$, while for ships whose engine rooms in the midship area of the ship experience losses of $3 \%$. In this plan, the engine room is located at the back, so that losses occur only $\eta \mathrm{S}=$ 0.98. So that the value of SHP is obtained, namely:

$$
\begin{aligned}
\text { SHP } & =\frac{D H P}{\eta_{S}} \\
& =\frac{369.6}{0.98} \\
& =377.14 \quad \mathrm{~kW}
\end{aligned}
$$

\section{6) Brake Horsepower}

$\mathrm{BHP}$ is the output power of the driving motor in the condition of continuous service rating (SCR), namely motor power in conditions of $80-85 \%$ of maximum continuous rating (MCR). Because the ship uses a gearbox so that there is a gearbox efficiency of $98 \%$. So the BHP value is as follows:

$$
\begin{array}{rlr}
\mathrm{BHP} & =\frac{S H P}{\eta_{G}} & \\
& =\frac{377.14}{0.98} & \\
& =384.84 & \mathrm{~kW} \\
& =516.078 & \mathrm{HP}
\end{array}
$$

\section{G. Validation of Calculation Power}

From the CFD simulation results, then a data comparison or validation is carried out between the calculation of Maxsurf Resistance using the Holtrop method because the ship is a displacement type with the Numeca Fine Marine CFD simulation resistance as follows. 
TABEL 5.

VALIDATION DATA

\begin{tabular}{|c|c|c|c|c|}
\hline No & Calculation & Power (HP) & Resistance (N) & Vs (Knot) \\
\hline 1 & $\begin{array}{c}\text { Calculation Maxsurf } \\
\text { Resistance }\end{array}$ & 614.660 & 40090.61 & 11.6 \\
\hline 2 & $\begin{array}{c}\text { Calculation Result Simulation } \\
\text { CFD Propeller Clerance } 0.738 \\
\mathrm{~m}\end{array}$ & 516.078 & 37716 & - \\
\hline 3 & $\begin{array}{c}\text { Exsisting MV. Mina Makmur } \\
150 \mathrm{GT}\end{array}$ & 657 & - & 7.821 \\
\hline
\end{tabular}

From Table 5 it is obtained existing at sea trial KM. Mina Makmur 150 GT with a power of 657 HP at a speed of 7,821 knots even though the initial target of the speed of the ship ranged from 10 to 11 knots. From the analysis of table 4.10 , the simulation value obtained 516,078 HP power, $37716 \mathrm{~N}$ resistance, and speed range $10-11$ knots with $0.738 \mathrm{~m}$ propeller disk actuator laying configuration from the AP line, so it can be concluded that the laying disk propeller actuator configuration affects the power and ship resistance so that the impact at an increase in the speed of service of the ship.

\section{CONCLUSION}

Based on the results of the simulation, analysis, and discussion that has been done in the previous chapter, there are some conclusions as follows:

1. The actuator disk propeller method is effective for measuring the parameters of thrust, torque, and rotation as well as $\mathrm{KT}, \mathrm{KQ}$, and $\mathrm{J}$ on a 150 GT Fishing Vessel which are used to model the propeller effect without modeling a real propeller by varying clearance actuator disk propeller. Where the ship's existing speed is 7,821 knots with $657 \mathrm{HP}$ power. After calculation and configuration of the actuator disk propeller, the speed is around 10-11 knots with an estimated power of 516,078 HP.

2. From the analysis and discussion it can be concluded that "D Configuration" at a distance of $0.738 \mathrm{~m}$ from the steering shaft reference point, has the most optimal propulsion efficiency with $\mathrm{KT}=0.22, \mathrm{KQ}=0.028$, and $\mathrm{J}$ $=0.40$ so that propulsion efficiency is $50 \%$.

3. From the analysis and discussion of the flow passing through the actuator disk propeller that the "D Configuration" has the largest and homogeneous flow with a value of 10.6 knots it occurs because of the adequacy of the propeller work area and the slope angle formed between the water and the longitudinal axis of the hull the stern part of the ship. An increase in advance velocity will have an impact on increasing propulsion efficiency so that the impact is on increasing service speed.

\section{REFERENCES}

[1] U. D. Kemenristek, Seri Desain Kapal Trdisional Pantai Utara Jawa, Jakarta: Kemenristek, 2014.

[2] I. Dwitara, "Analisa Aliran dan Tekanan pada Perubahan Bentuk Skeg Kapal Tongkang dengan Pendekatan CFD," JURNAL TEKNIK POMITS, p. 2, 2013.

[3] M. Ridwan and S. , "Parameter Desain Propeller Kapal," Teknik Perkapalan Undip, p. 2, 2008.

[4] I. M. Ariana, Tahanan dan Propulsi Kapal, Surabaya: Jurusan Teknik Sistem Perkapalan-ITS, 2009.

[5] S. A. Harvald, Tahanan dan Propulsi Kapal, Surabaya: Airlangga University Press, 1992.

[6] A. Sahid and N. Siswantoro, Desain II Propeller dan Sistem Perporosan, Surabaya, 2017.

[7] Y. Hidayat, B. T. Musriyadi and A. , Analisa Aliran Fluida Terhadap Penambahan Pre-Swirl Pada Lambung Kapal dengan Menggunakan CFD, Surabaya: Teknik Sistem Perkapalan-ITS, 2018

[8] M. Suranto and I. S. Arief, "Surface Cavitation Analysis on The Propeller Wageningen Blades Series C4-40 Using CFD," Int. J. of Marine Engineering Innovation and Research, p. 2, 2018.

[9] S. W. Adji, Engine Propeller Matching, 2005.

[10] Y. N. Win, Computation of the Propeller-Hull and PropellerHull-Rudder Interaction Using Simple Body-Force Distribution Model, Osaka: Graduate School of Engineering, Osaka University, 2014.

[11] M. Manna and R. Bontempo, "Actuator disc methods for open propellers: assessments of numerical methods," Informa UK Limited, trading as Taylor \& Francis, p. 7, 2017.

[12] B. Roy, "Introduction to Aerospace Propulsion," Department of Aerospace Engineering, IIT Bombay, Bombay.

[13] K. B. Korkmaz, CFD Predictions of Resistance and Propulsion for the JAPAN Bulk Carrier (JBC) with and without an Energy Saving Device, Gothenburg, Sweden: Department of Shipping and Marine Technology, Chalmers University Technology, 2015.

[14] N. O. D. Platform, Theory of Actuator Disk Propeller,

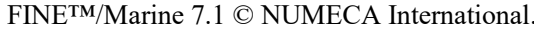

[15] A. Santoso and B. P. Pratama, Redesain Amphibious Rescue Boat Kasrat X-1 Sebagai Langkah Optimalisasi Hull Resistance dan Daya Engine, Surabaya: Jurusan Teknik Sistem Perkapalan-ITS, 2018.

[16] E. Jadmiko, L. Arif and I. S. Arief, "Comparison of Stern Wedge and Stern Flap on Fast Monohull Vessel Resistance," International Journal of Marine Engineering Innovation and Research, p. 43, 2018.

[17] A. H. Muhammad, H. Hasan and Jusman, "Desain Kriteria Propeller Clearance Kapal Tradisonal Tipe Pinisi," Jurnal JPE, vol. 20 , p. 4, 2016 . 